\title{
Full Stress Tensor Determination during Phase Transformation of a Metal Matrix Composite by in situ High Energy X-Ray Diffraction and Micromechanical Simulations
}

\author{
Guillaume Geandier ${ }^{\mathrm{a}, 1,{ }^{*}}$, Lilian Vautrot ${ }^{\mathrm{b}, 1}$, Benoît Denand ${ }^{\mathrm{c}, 1}$, Moukrane Dehmas ${ }^{\mathrm{d}, 1}$, \\ Elisabeth Aeby-Gautiera $^{\mathrm{e}, 1}$, Julien Teixeira ${ }^{\mathrm{f}, 1}$. Sabine Denis ${ }^{\mathrm{g}, 2}$ \\ ${ }^{1}$ Institut Jean Lamour, CNRS - Université de Lorraine, Parc de Saurupt - CS 50840, 54011 \\ Nancy Cedex - France \\ ${ }^{2}$ LabEx DAMAS - Université de Lorraine, Parc de Saurupt - CS 50840, 54011 Nancy Cedex - \\ France \\ aguillaume.geandier@univ-lorraine.fr, 'blilian.vautrot@univ-lorraine.fr, 'benoit.denand@univ- \\ lorraine.fr, ${ }^{d}$ moukrane.dehmas@univ-lorraine.fr, eElisabeth.Gautier@univ-lorraine.fr, \\ fjulien.teixeira@univ-lorraine.fr, ${ }^{9}$ sabine.denis@univ-lorraine.fr
}

Keywords: Metal Matrix Composite, in situ X-Ray Diffraction, Stresses, Phase Transformation, Microstructure

\begin{abstract}
In situ high energy X-ray diffraction using a synchrotron source performed on a steel metal matrix composite reinforced by $\mathrm{TiC}$ allows following the evolutions during cooling of internal stresses thanks to the development of a new original experimental device (a transportable radiation furnace with a controlled rotation of the specimen). Results from experiments as well as from finite element micromechanical simulations allow to understand the stress genesis in the composite.
\end{abstract}

\section{Introduction}

Mass reduction (for example in transportation applications where reduction of fuel consumption and pollution are aimed) can be obtained, by using new lighter materials with at least the same mechanical properties as the former ones. Metal Matrix Composites (MMC) reinforced by ceramic particles allow reaching this goal. In our study, steel matrix composite reinforced by TiC particles obtained by powder metallurgy (mixture of $75 \%$ steel powder and $25 \% \mathrm{TiC}$ powder) allows reducing the density $\left(7 \mathrm{~g} / \mathrm{cm}^{3}\right.$ for this composite instead of $7.8 \mathrm{~g} / \mathrm{cm}^{3}$ for steel alone i.e. a decrease of $11.4 \%$ in mass). Final properties of MMC depend on the chemical composition, on the nature of the interfaces, on the microstructure of the matrix and on the stresses in the reinforcements and in the matrix. These stresses are generated during the heat treatment and result from the differences in the coefficient of thermal expansion between matrix and reinforcements [1-3] and also from the phase transformations of the matrix that occur during cooling and induce volume changes. The residual stress levels and distributions are a key factor for the final properties of the MMC [4]. In a previous study [5], the evolution of the matrix and the reinforcements were analysed during the heat treatment using in-situ high energy $\mathrm{X}$ ray diffraction focusing on the structural aspects. In this paper, we focus on the internal stress analysis.

\section{Sample}

A metal matrix composite has been elaborated using powder metallurgy by Mecachrome. $75 \%$ (vol.) steel powder and $25 \%$ TiC powder were milled and consolidated by hot isostatic pressing (HIP). After hot isostatic pressing, the microstructure of the steel matrix composite (see fig. 1) is nonhomogeneous and presents two different areas: a steel area (pearlitic) without TiC particles called unreinforced area (lighter area) and a darker area being a mixture of TiC particles and steel. Details on the microstructures and chemical compositions can be found in [5]. 

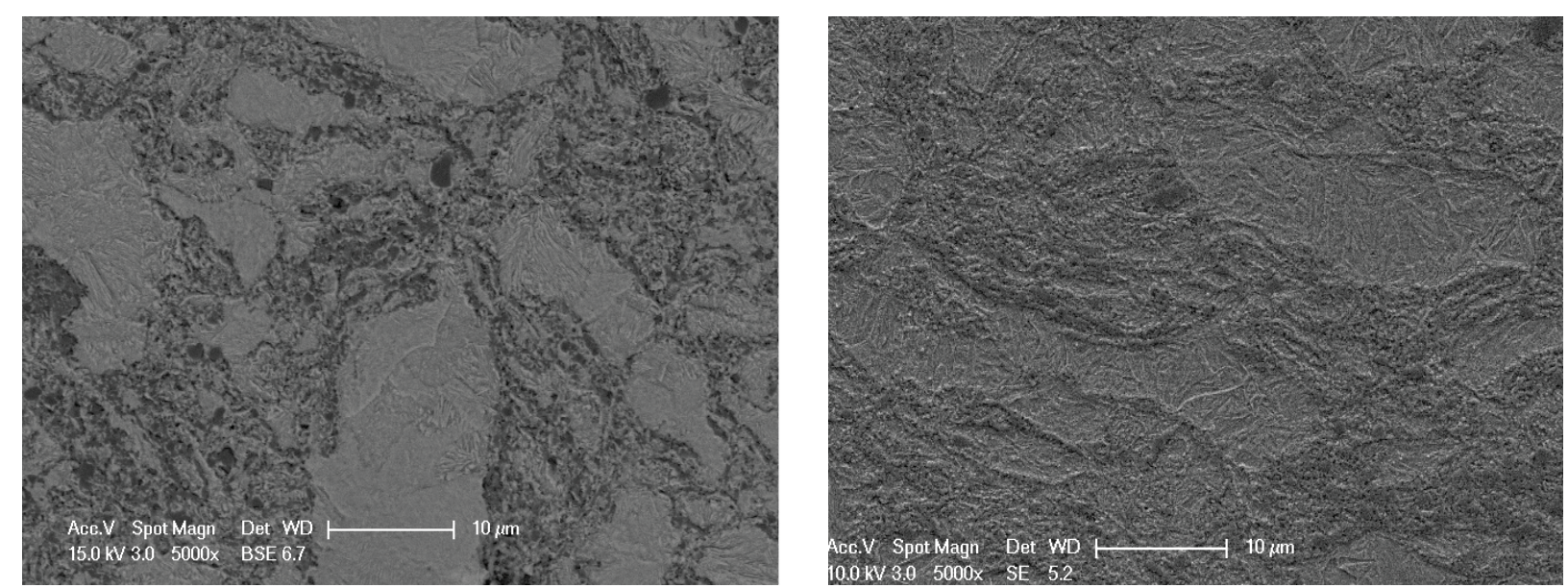

Figure 1: MMC microstructure at initial state (left) and after thermal treatment with a martensitic microstructure (right) in the matrix

\section{High-energy X-ray diffraction.}

Set-up : The high energy X-ray diffraction (XRD) experiments were performed at the European Synchrotron Radiation Facility (ESRF, Grenoble, France) on the ID15B beam line. The in situ measurements were conducted with a monochromatic beam of $87 \mathrm{keV}$. The high energy beam allowed to analyse a large volume of the sample (due to the low absorption of the sample) thus being representative of the bulk and lessen the surface effect. The transmitted signal is collected by a large area $2 \mathrm{D}$ detector that records the whole Debye-Scherrer rings. The important flux gives a high quality diffraction signal quickly, thus XRD frames can be recorded at high rate (up to $10 \mathrm{fps}$ ). By this method, we can follow Debye-Scherrer rings evolution during a thermal treatment. More details on the setup can be found in [6].

For our experiments, the sample was a cylinder of $3 \mathrm{~mm}$ diameter and $30 \mathrm{~mm}$ length and the beam size was $0.4 \times 0.4 \mathrm{~mm}^{2}$. The sample was heated up to $900^{\circ} \mathrm{C}$ thanks to a radiation furnace specially developed to performed a thermal treatment with a controlled rotation of the sample. The temperature was held during 5 minutes. Then, the sample was air cooled (at about $5{ }^{\circ} \mathrm{C} / \mathrm{s}$ ). XRD frames were recorded every $0,1 \mathrm{~s}$ during cooling. Using the sample rotation during in situ cooling and a fast acquisition rate allows collecting the data to determine the full stress tensor as we obtain all necessary orientations of the sample by combining the rotation in plane of the sample and 2D diffraction in the perpendicular plane.

Phase analysis : As the sample presents small grains and no texture during the whole thermal treatment, a Rietveld analysis has been conducted to extract phase fractions and mean cell parameters from the XRD frames using Fullprof software [7-8]. Data have been corrected and reduced to (2 $\theta$, intensity) patterns using fit2D software [9].

Stresses analysis : For stress analysis, 2D images caking has been made with sectors of $1^{\circ}$ along the rings using fit2D software. Corrections for taking into account the variations of frame center during the experiments (due to a lack of stability of the synchrotron beam) [10] as well as the variations of the sample position during rotation have been done. Thus, we obtain 360 diffractograms ( $2 \theta$, intensity) from each image. In order to extract the stresses in each phase from these data, we have determined the $2 \theta$ position of one peak in each phase: steel- $\alpha^{\prime}(200)$, steel- $\gamma(200)$ and $\mathrm{TiC}(220)$, as they do not overlap with other peaks (fig. 2). Diffraction peaks are approximated by a Pearson VII function. In order to apply the " $\sin ^{2} \Psi$ " method [11-12], we have converted our configuration to classical $(\Phi, \Psi)$ configuration [6]. 
By selecting the rotation position corresponding to a specific orientation of the sample, we can extract the $\sigma_{11}-\sigma_{33}$ and $\sigma_{22}-\sigma_{33}$ differences from positions $\left(0^{\circ}, 180^{\circ}\right)$ and $\left(90^{\circ}, 270^{\circ}\right)$ versus temperature. An automatic procedure (about 10 million peaks to be analysed per phase, 150GB raw data) has been developed.

To obtain the full strain and stress tensor, we need the stress free parameters of the phases $\mathrm{a}_{0}$ and their evolutions with temperature. For steel- $\gamma$ and $\mathrm{TiC}$, we have used the value of the cell parameter at high temperature assuming that stresses are fully relaxed at $900^{\circ} \mathrm{C}$ and for martensite values from literature [13]. Evolution of stress free cell parameter versus temperature has been calculated using the thermal expansion coefficient of each phase, extracted from experimental studies [5] or literature for steel [14] and $\mathrm{TiC}[15]$.
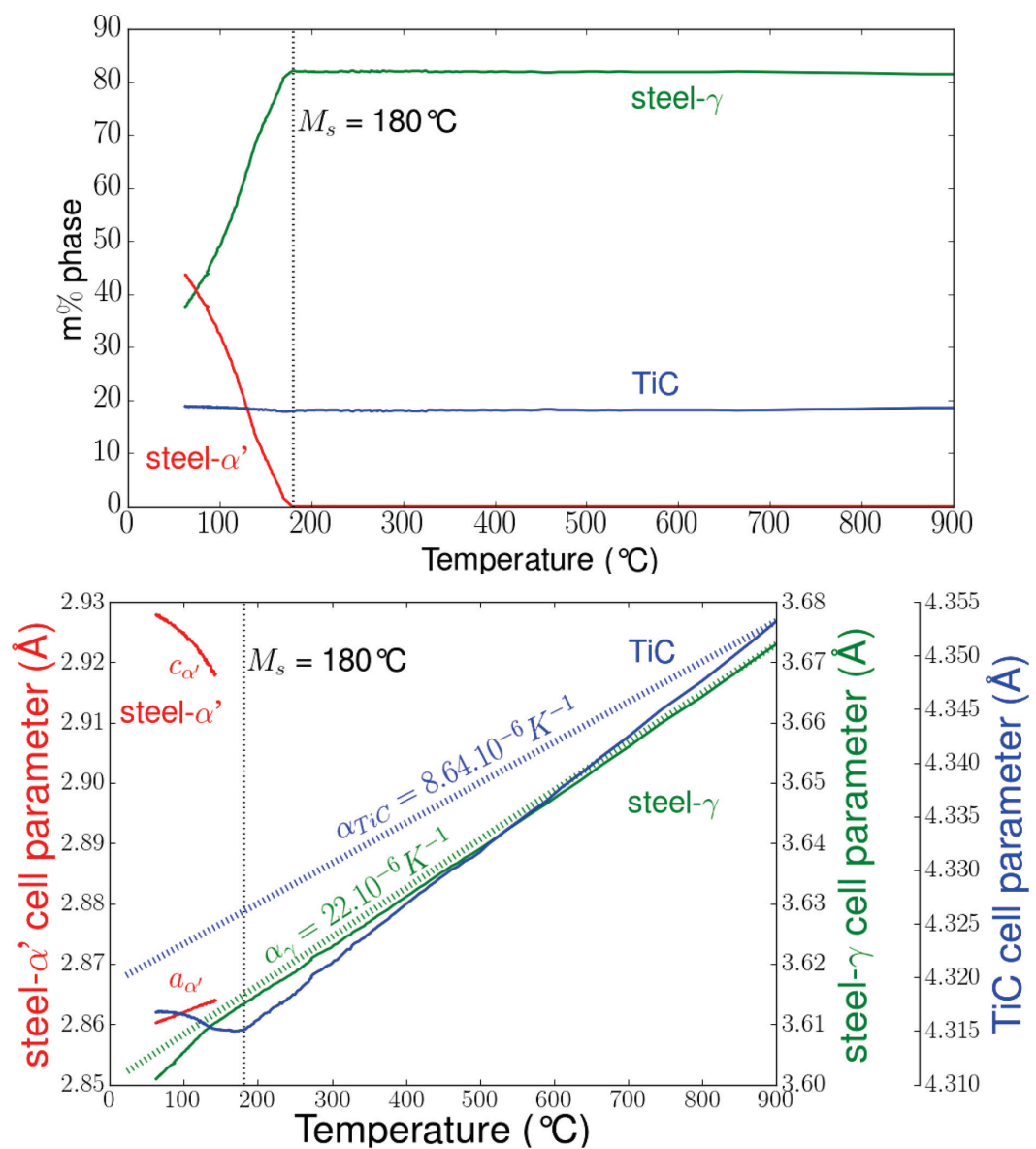

Figure 2 : Evolutions during cooling a) phase fractions and b) cell parameters (thermal expansion coefficients of TiC and austenite are shown too)

\section{Results}

Kinetics of phase transformation: on figure 2, we present the evolutions of the phase fractions and the mean cell parameters during the cooling from $900{ }^{\circ} \mathrm{C}$ to $50{ }^{\circ} \mathrm{C}$, leading to the formation of martensite in the matrix (see fig. 1). At the beginning of the cooling, only austenite $(\gamma)$ and TiC are present with $81 \mathrm{~m} \% \gamma$ and $19 \mathrm{~m} \%$ TiC. The martensitic transformation ( $\alpha$ ' tetragonal structure) begins at $180^{\circ} \mathrm{C}$. During the cooling, the amount of $\mathrm{TiC}$ remains constant and the amount of austenite decreases quickly during the martensitic transformation.

Mean cell parameters evolutions: from the beginning of cooling and until the beginning of martensitic transformation, the cell parameters of the different phases decrease continuously without changes of slope (fig. 2b). From previous analysis [16] of the apparent CTE (coefficient of thermal 
expansion), it was concluded that during cooling, thermal stresses are generated in the phases. TiC is under a mean compression state since the CTE of austenite is about 3 times larger than the one of TiC. The mean stress state in austenite seems very small. As the martensitic transformation occurs, $\mathrm{TiC}$ cell parameter increases indicating a decrease of the mean compression in TiC. As the martensite content reaches about $15 \%$, austenite cell parameter decreases indicating an increase in compression. We can observe an increase of the tetragonality (c/a ratio) of the martensite (increase of the c parameter whereas a parameter decreases linearly).

Stress evolutions: using $\sin ^{2} \psi$ method, we are able to determine all the components of the stress tensors in the different phases during cooling. First, it comes out that the mean stress states remain hydrostatic (no shear stresses) in all the phases during cooling even during the martensitic transformation. Fig. 3 presents the stress evolutions during cooling from $900^{\circ} \mathrm{C}$ to $50^{\circ} \mathrm{C}$.

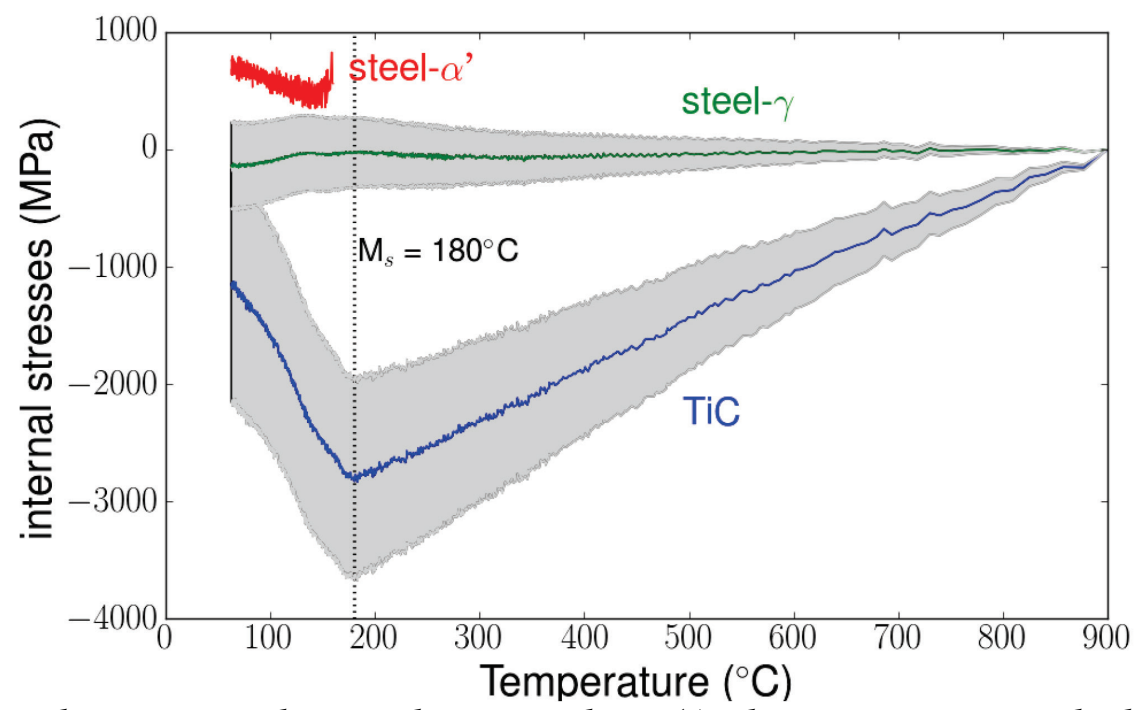

Figure 3 : internal stresses evolutions during cooling. (As the stress states are hydrostatic, only one component of the stress tensor is presented)

We can remark the high level of compressive stress in $\mathrm{TiC}$ increasing from the high temperature until the appearance of martensite. Stress level in austenite is quite low. The martensitic transformation induces a large decrease of the compressive stress in $\mathrm{TiC}$ and small compressive stresses in austenite. For martensite, firstly the tensile stress decreases and then increases as temperature decreases.

We can notice that the calculated macroscopic stress for the composite, is not zero even before the phase transformation. It should be pointed out that stress values are highly dependent on the input parameters of each phase mainly $\mathrm{a}_{0}$ and CTE. On figure 3 , the grey envelope presents the variations on the stress levels for austenite and $\mathrm{TiC}$ including experimental uncertainties on the thermal expansion coefficient of both phases. (For martensite, the stress variations are not shown as they will overlap the stress scattering). It comes out that variations on the stress levels are quite large and a more equilibrated macroscopic stress state could be reached by adjusting the stress free cell parameters and their evolutions with temperature.

Micromechanical model

In order to better understand the internal stress evolution during cooling of the MMC, a 3D micromechanical finite element model has been used (software ZeBuLoN [17]). We have introduced a thermo-elasto-visco-plastic behaviour law for the steel matrix including the strains associated with the phase transformation (volumic variation and transformation plasticity). All the thermomechanical data for the steel are taken from previous studies. For the reinforcement, a thermo-elastic behaviour 
law is taken into account based on literature data [14]. Martensite phase fraction is calculated by Koistinen-Marburger relation [18] with parameters determined from experimental data.

Calculations have been made on a 3D simplified microstructure: a periodic distribution of spherical TiC particles (representing 25vol\%) embedded in a steel matrix.
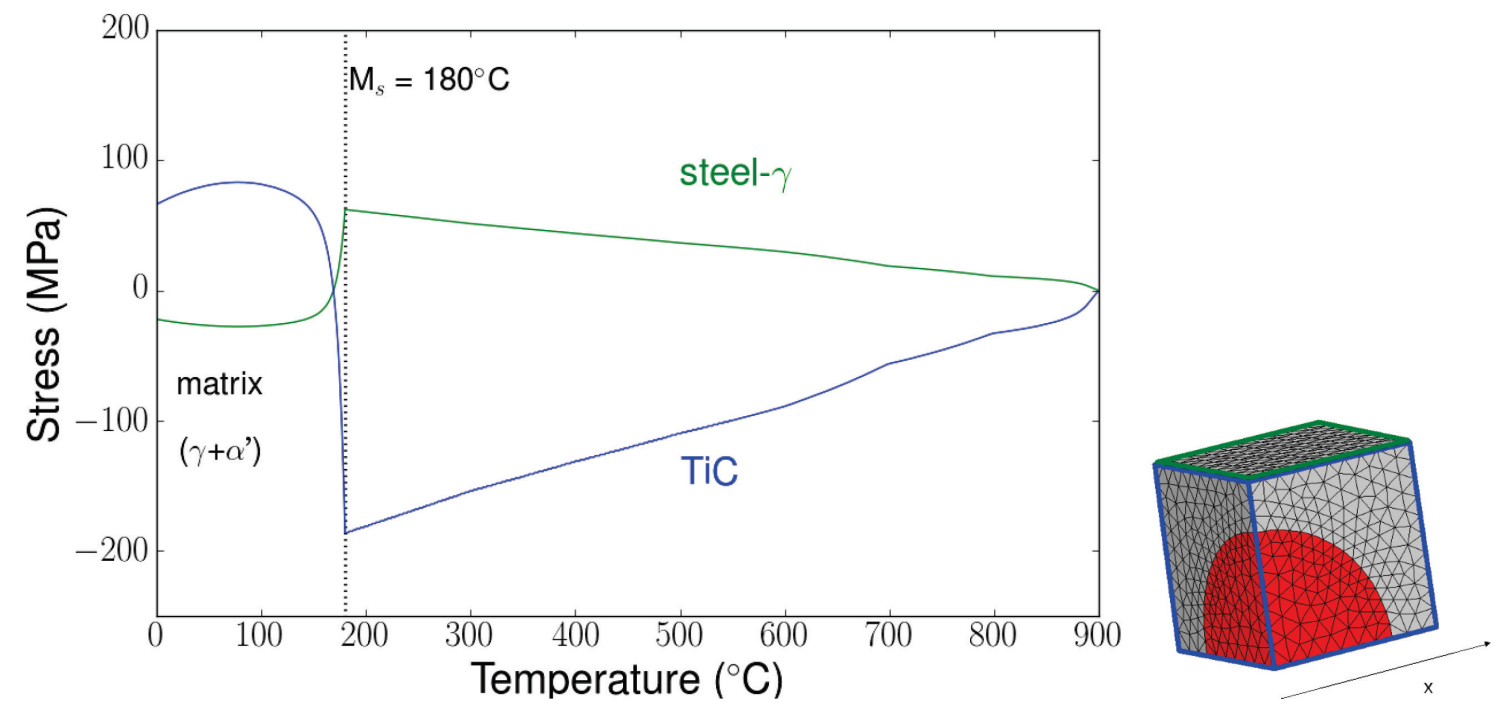

Figure 4 : mean stresses evolution calculated by FEM.

The calculated results allow to analyse the stress and strain gradients in the reinforcement and in the matrix during cooling as well as the permanent deformations in the matrix. Here, we show only the mean stresses in the particles and in the matrix (figure 4) that are hydrostatic. Their evolutions are in accordance with the experimental results; in particular, the martensitic transformation of the matrix (with its volumic expansion) leads to a large stress relaxation in the TiC particles and to a lower one in the matrix. But the calculated levels differ largely from the experimental values in particular for TiC. The thermo-elasto-visco-plastic behaviour of the matrix seems to overestimate the stress relaxation by plastic deformation. As a matter of fact, if we do not consider plastic deformation of the matrix, considering an elastic behaviour, we obtain calculated mean stress values for TiC closer to experimental ones. Moreover, from the calculations, the cumulated equivalent plastic deformation reaches a value of $3 \%$ in the matrix whereas experimentally we due not observe a change on the full width at half maximum (FWHM) of the austenite peaks during cooling.

Thus, the question arises concerning the strain accommodation between the matrix and particles in the MMC during cooling. One important aspect is that the real microstructure is much more complex that the simulated one. Indeed, as mentioned before, the real microstructure is very heterogeneous (see fig. 1) with a non reinforced area (no particles) and a reinforced area where the amount of TiC can reach $50 \mathrm{vol} \%$. Calculations are on the way to take the real microstructure into account.

\section{Concluding remarks}

We have developed an original experimental device and a methodology for robust and fast stress analysis starting from 2D images (i.e. Debye-Scherrer rings) obtained by in situ synchrotron X ray diffraction experiments during heat treatment. From the present experiments performed during heat treatment of a steel matrix composite reinforced by $\mathrm{TiC}$ particles, we have determined the evolutions of the full stress tensor in the different phases austenite, martensite and $\mathrm{TiC}$. The role of the martensitic transformation of the matrix on the stress states in the particles has been clearly evidenced. In addition, a 3D micromechanical approach has allowed to better interpret the experimental evolutions of the mean internal stress states in the different phases during cooling. Further investigations are necessary to understand the discrepancies between experimental and calculated stress levels. 


\begin{abstract}
Aknowledgments
The authors gratefully acknowledge Mecachrome for supplying the materials, the Direction Générale des Entreprises (DGE) for financial support in the AMETIS program and the European Synchrotron Radiation Facility (ESRF) for provision of beamtime at beamline ID15B. This work was supported by the French State through the program "Investment in the future" operated by the National Research Agency (ANR) and referenced by ANR-11-LABX-0008-01 (LabEx DAMAS).
\end{abstract}

\title{
References
}

[1] Meixner M., Fitzpatrick M. and Reimers W.: Composite Science and Technology, Vol. 71 (2011), p. 167-176. http://dx.doi.org/10.1016/j.compscitech.2010.11.003

[2] Lee R., Chen G. and Hang B.: Composites, Vol. 26 (1995), p. 425-429. http://dx.doi.org/10.1016/0010-4361(95)90915-M

[3] Pagounis E., Haimi E., Pietikaïnen J., Talvitie M., Vahvaselkä S. and Lindroos V.K.: Scripta Materialia, Vol. 34 (1996), p. 407-413. http://dx.doi.org/10.1016/S0956-716X(95)00529-5

[4] Wu Y., Wang M., Chen Z., Ma N. and Wang H.: Materials Science, Vol. 48 (2013) p. 2928-2933. http://dx.doi.org/10.1007/s10853-012-6933-x

[5] Mourot M., Courleux A., Dehmas M., Gautier E., Geandier G., Dezellus O., Viala J.C., Martin O., Karnatak N. and Danoix F.: Solid State Phenomena, Vol. 172-174 (2013), p. 747-752. http://dx.doi.org/10.4028/www.scientific.net/SSP.172-174.747

[6] Vautrot, L.; Geandier, G.; Mourot, M.; Dehmas, M.; Aeby-Gautier, E.; Denand, B. \& Denis, S. François, M.; Montay, G.; Panicaud, B.; Retraint, D. \& Rouhard, E. (Eds.), Trans Tech Publications, Switzerland, 2014, 996, 944-950

[7] Rietveld H.M.A. : Journal of Applied Crystallography, Vol. 2 (1969), p. 65-71. http://dx.doi.org/10.1107/S0021889869006558

[8] Rodriguez-Carvajal J.: Physica B, Vol. 192 (1993), p. 55-59. http://dx.doi.org/10.1016/09214526(93)90108-I

[9] Hammersley A.P., Svensson S.O., Thompson A., Graafsma H., Kvick A. and Moy J.P.: Review of Scientific Instrument, Vol. 66 (1995), p. 2729-2733. http://dx.doi.org/10.1063/1.1145618

[10] Le Bourlot, C., Caractérisation de l'hétérogénéité du champ des déformations élastiques dans les matériaux polycristallins par diffraction des rayons $\mathrm{X}$ et des neutrons - application à un acier duplex $\mathrm{PhD}$ thesis (2012) Université Paris 13, France

[11] Noyan I.C. and Cohen J.B.: Measurement by diffraction and interpretation in residual stress, Springer-Verlag, (1987)

[12] Hauk V., Structural and reisudual stress analysis by nondestructive methods, ELSEVIER, (2006)

[13] Roberts C.S.: Journal of Metals, 5 (1953) 203-204

[14] Vidal G., Lescop P. and Raymondin L.: Revue de métallurgie 48, Vol. 11 (1951), p. 864874

[15] Wall J., Choo H., Tiegs T. N. and Liaw P. K.: Materials Science and Engineering A, Vol. 421 (2006), p. 40-45. http://dx.doi.org/10.1016/j.msea.2005.10.002

[16] Geandier G., Dehmas M., Mourot M., Aeby Gautier E., Denis S., Martin O. and Karnatak N.: Materials Science Forum, Vols. 768-769 (2014), p. 313-320. http://dx.doi.org/10.4028/www.scientific.net/MSF.768-769.313

[17] Besson J., Leriche R., Foerch R. And Cailletaud G., Revue Européenne des Éléments, 7:5 (1998) 567-588

[18] Koistinen D.P., Marburger R.E., Acta Metallurgica, 7 (1959) 59-60. http://dx.doi.org/10.1016/0001-6160(59)90170-1 